\title{
Electro-tribological properties of diamond like carbon coatings
}

\author{
Iñigo BRACERAS ${ }^{1,{ }^{*}}$, Iñigo IBÁÑEZ ${ }^{1}$, Santiago DOMINGUEZ-MEISTER ${ }^{1}$, Xabier VELASCO ${ }^{2}$, Marta BRIZUELA ${ }^{1}$, \\ Iñaki GARMENDIA ${ }^{2}$ \\ ${ }^{1}$ Tecnalia Research \& Innovation, Mikeletegi Pasealekua 2, Donostia-San Sebastián 20009, Spain \\ ${ }^{2}$ Mechanical Engineering Department, University of the Basque Country UPV/EHU, Plaza de Europa, 1, Donostia-San Sebastián 20018, Spain \\ Received: 09 November 2018 / Revised: 12 January 2019/Accepted: 04 March 2019 \\ (C) The author(s) 2019.
}

\begin{abstract}
Diamond like carbon (DLC) coatings typically present good self-lubricating tribological properties that could be of interest in sliding dielectric contacts in multiple electrical applications. In this work electro-tribological studies have been performed on several DLC coatings against aluminum in different humidity conditions, in which the coefficients of friction ( $\mathrm{CoFs}$ ) and electrical contact resistance (ECR) were continuously monitored. Results show that CoF and ECR data can be linked to the properties of the coatings (thickness, finishing, microstructure, residual stresses, and wettability) and the degradation modes of their tribological and electrical properties. Therefore, electro-tribological data can provide valuable information about the performance of dielectric coatings, the reasons behind it, and assist in the development of the coatings. ECR also shows potential for on-line monitoring of coated parts in operation.
\end{abstract}

Keywords: DLC; electro-tribology; ECR-electrical contact resistance; coefficient of friction

\section{Introduction}

Sliding dielectric contacts require of durable and dependable tribological surfaces, in a variety of increasing applications such as in electrical and hybrid transport vehicles [1-7]. Among the solid lubricant coatings, one of the most promising alternative is diamond like carbon (DLC) [8]. The family of DLC coatings exhibits a wide variety of tribo-mechanical and electrical properties, depending among others on their composition and structure [8-13]. The electrical properties of DLC coatings can actually vary from that of a semimetal to that of an insulator [5, 14]. It has been demonstrated that dielectric hard DLC coatings can be obtained with good tribological properties [15-18]. Dielectric coatings with good tribological properties can be useful in sliding dielectric coating setups, e.g. to transition from conducting to nonconduction operative stages without physical detachment of the electrodes. Low steady friction coefficients of
DLC coatings have been related to the formation of carbon-rich transfer layers on the counterface, caused by friction induced annealing by thermal and strain effects generated during sliding. It has also been proposed that bonding into the DLC surface of oxygen and hydrogen reduces the possibility for the formation of bonds between the DLC coating and its counterface, originating low friction forces [19-22]. Furthermore, aspects such as the internal stresses of the coatings or the relative humidity of the working environments are known to play an important role in their tribology performance [21, 23, 24].

Monitoring of the coating status and evolution can provide a valuable tool regarding the dependability of coatings/systems in critical applications and/or difficult to access locations [25-30]. Along these lines, monitoring of the dielectric coating degradation in sliding conditions, due to wear or other coating degradation mechanisms, can be helpful in the framework of defining a predictive approach of a

* Corresponding author: Iñigo BRACERAS, E-mail: inigo.braceras@tecnalia.com 
dependable coating operating life [4, 31]. Actually, usage of DLC coatings with different electrical properties have already been studied in fatigue damage sensors [32], being crack formation and propagation one of the potential degradation mechanisms of dielectric DLC coatings. Furthermore, this can also be valuable in the framework of coating process development and optimization studies, as coating failure modes can be related to coating deposition process parameters, evolution, and degradation of the dielectric properties, testing or operating conditions, etc. [33]

This paper details the electro tribological studies performed on DLC dielectric coatings deposited on copper, focusing on the evolution of the electrical contact resistance characteristics and their tribological properties, as well as the coating degradation mechanisms. Aluminum is the selected counterpart, as one of the most used material in electric and electronic applications together with copper, is inexpensive and because typically presents a challenging tribology behavior [3,29]. Additionally, the use of electro tribological data as a monitoring tool of the coating operative life is explored. This could be of interest not only in electrical applications, but also in $\mathrm{Al}$ part forming operations, where DLC coated tools are often used.

\section{Material and methods}

Diamond like carbon (DLC) coatings were deposited on electrical grade mirror polished copper disks, $50 \mathrm{~mm}$ in diameter and $5 \mathrm{~mm}$ thick (Cu-Etp EN-13601 R250; Bronmetal, Spain), and in $8 \mathrm{~mm} \times 40 \mathrm{~mm}$ silicon coupons. Electro-tribology studies were performed against $6 \mathrm{~mm}$ diameter aluminum (99.7\%) balls.

Prior to the DLC coating deposition, the copper surface was sputter cleaned with argon. Then, an intermediate $0.1 \mu \mathrm{m}$ thick WC-Co interlayer was deposited to improve the adhesion of the DLC coating to the copper substrate, using WC- $6 \%$ Co targets, by magnetron sputtering (cathode power $500 \mathrm{~W}$ ) with $\mathrm{Ar}$ at a pressure of 0.4-0.9 $\mathrm{Pa}$. Subsequently, hydrogenated amorphous carbon (a-C:H) DLC coatings were deposited in the same (CEMECON CC800/8 plus, Germany) physical vapor deposition magnetron sputtering (PVD-
MS) unit, with acetylene $\left(\mathrm{C}_{2} \mathrm{H}_{2}\right)$ as the carbon source gas, at low temperature $\left(<150{ }^{\circ} \mathrm{C}\right)$, for a deposition time of 110 minutes. Coating deposition parameters are detailed in Table 1.

Coating composition and structure were analyzed by Raman (1,000 to $1,900 \mathrm{~cm}^{-1}$ with an excitation wave length of $514 \mathrm{~nm}$; In via Reflex, Renishaw), electrical scanning microscopy (SEM) and energy dispersive spectroscopy (EDS) (JEOL JSM-5910LV). Raman analyses, with the interpretation of the results following the work of Ferris and Robertson [34-36], provided $I(\mathrm{D}) / I(\mathrm{G})$ ratios estimates, though the limitations with visible Raman to produce accurate quantitative data in DLC films should be noted [37].

Surface wettability and roughness were quantified by water contact angle following IEC TS 62073 [38] (Digidrop, GBX) and contact profilometry (Veeco DEKTAK 150), respectively. The coating thickness and residual stresses were also determined by profilometry on coatings deposited onto silicon coupons. In the latter case, both the length $(L)$ and the height $(H)$ of the curvature were measured, and the residual stresses were calculated according to the Stoney formula.

Electro-tribology tests of aluminum against DLC coatings were performed on a pin-on-disk (PoD) configuration, in controlled humidity environments, with a Microtest MT4002 tribometer (Microtest S.A.), where the evolution of the Coefficient of friction $(\mathrm{CoF})$ and electrical contact resistance (ECR) were continuously monitored [29, 39]. The ECR measurements were done by " 4 wire" micro-ohmeter (Keithley K2100). Main test conditions consisted of a load of $3 \mathrm{~N}$, which corresponded to an initial mean contact pressure of approximately $350 \mathrm{MPa}$, and a speed of $50 \mathrm{~cm} / \mathrm{s}$ at room temperature. Relative humidity was usually $50 \%$, but varied in some cases to much lower and higher values, $10 \%$ and $90 \%$. After the electro-tribology tests, wear tracks were assessed by optical microcopy (OM; Olympus BX51M), SEM/EDS and profilometry.

Table 1 DLC coating deposition parameters.

\begin{tabular}{cccc}
\hline Reference & $V_{\text {bias }}(\mathrm{V})$ & $\mathrm{Ar}_{2} \mathrm{C}_{2} \mathrm{H}_{2}(\mathrm{mLN})$ & Pressure $(\mathrm{mPa})$ \\
\hline \#DLC & $5-10$ & $100: 50$ & 450 \\
\#DLCCH & $5-10$ & $100: 100$ & 460 \\
\#DLCVB & 150 & $100: 50$ & 450 \\
\hline
\end{tabular}




\section{Results and discussion}

\subsection{Coating properties}

Coating properties are detailed in Table 2. Reference\# DLC presented a coating thickness of $0.58 \mu \mathrm{m}$ (including a $0.1 \mu \mathrm{m}$ thick interlayer), an estimated $I(\mathrm{D}) / I(\mathrm{G})$ ratio, of 0.47 and an initial contact angle of $69.4^{\circ}$, that dropped to $63.5^{\circ}$ after one minute. The coating surface roughness was $R a 18 \mathrm{~nm}$.

In comparison, coating reference\#DLCCH was thicker $1.3 \mu \mathrm{m}$ (including a $0.1 \mu \mathrm{m}$ thick interlayer), presented a lower estimated $I(\mathrm{D}) / I(\mathrm{G})$ ratio of 0.44 , but larger contact angle, $78.4^{\circ}$. The coating roughness was similar: $R a 18 \mathrm{~nm}$. Therefore, an increase in acetylene in the gas mix during the coating deposition, increased the coating thickness, but produced a more hydrophobic coating.

Concerning the reference\#DLCVB coating, the thickness was similar to that of reference\#DLC, i.e. $0.52 \mu \mathrm{m}$ (including a $0.1 \mu \mathrm{m}$ thick interlayer), the estimated $I(\mathrm{D}) / I(\mathrm{G})$ ratio at 0.43 was even lower than in reference\#DLCCH, and the contact angle measured was $76.4^{\circ}$. On the other hand, the coating was rougher than the other references, with $R a 81 \mathrm{~nm}$. Therefore, an increase in the applied voltage bias during the coating deposition increased the coating roughness and the hydrophobicity.

The differences in the coating compressive residual stresses were also significant, with both higher applied voltage bias and larger acetylene in the gas mix producing less stressed coatings. On the other hand, in all cases the wettability increased with the time. The increased ion bombardment of the sample surface when the coating was being deposited, due to the bias voltage, which increases the ion current density and the ion energy, at the voltage value applied caused a higher sputtering process and thus a rougher surface and some re-sputtering effect, which tends to originate softer coatings. For the same reason, residual stresses declined with higher bias voltage. The phenomena of an increase in the residual stress with the bias voltage up to a point and a subsequent fall after a certain bias voltage value has already been observed by several authors. When larger acetylene was present in the gas mix, ion bombardment also increased, but with smaller and not so energetic ions, thus the sputtering and re-sputtering phenomena were not as severe, and there was no modification of the surface roughness. Moreover, as the coating was deposited at a faster rate, the lattice distortion and disorder effect and overall imperfections were annealed out less efficiently, so the internal stresses originated were at an intermediate level [40-42].

\subsection{Electro-tribology}

Electro-tribological behavior of the different variations of DLC coatings were carried out, including different humidity conditions. Unlike in electrically conductive counterparts, the electrical current was not a key parameter in these studies [4, 43], because all studied DLC coatings were dielectric. The evolution of the electrical contact resistance and the coefficient of friction in the tests, typically presented a number of distinct phases. These are depicted as regions A, B, C, D, and E in Fig. 1.

In the case of reference\#DLCCH, an initial phase, where the CoF increased and the ECR stayed high (above the measuring limit of the equipment) can be associated to the wear of the aluminum ball surface, the ensuing change in the surface material as the aluminum oxide initially present in the contact surface was gradually removed (Region A in Fig. 1(a)).

In the ensuing phase, the contact area and pressure stabilized, a DLC transfer layer formed in the aluminum counterpart (Fig. 2), some mild adhesive wear occurred, but both the CoF and ECR remained steady (Region B in Fig. 1(a)). Next, cracks began to appear in the coating, and the ECR decreased gradually, with the

Table 2 DLC coating characteristics.

\begin{tabular}{|c|c|c|c|c|c|c|c|}
\hline \multirow{2}{*}{ Reference } & \multirow{2}{*}{$I(\mathrm{D}) / I(\mathrm{G})$} & \multirow{2}{*}{$\begin{array}{c}e \\
(\mu \mathrm{m})\end{array}$} & \multirow{2}{*}{$\begin{array}{c}R a \\
(\mathrm{~nm})\end{array}$} & \multirow{2}{*}{$\begin{array}{l}\text { Residual stress } \\
(\mathrm{MPa})\end{array}$} & \multicolumn{2}{|c|}{ Contact angle $\left({ }^{\circ}\right)$} & \multirow{2}{*}{$\begin{array}{c}\text { Coating life } t_{\mathrm{ABC}} \\
\text { (cycles) }\end{array}$} \\
\hline & & & & & $t=0$ & $t=60 \mathrm{~s}$ & \\
\hline \#DLC & 0.47 & 0.58 & 18 & -16.9 & $69.4 \pm 1.6$ & $63.5 \pm 2.0$ & 48,000 \\
\hline \#DLCCH & 0.44 & 1.33 & 18 & -8.3 & $78.4 \pm 1.9$ & $70.5 \pm 0.5$ & 161,000 \\
\hline \#DLCVB & 0.43 & 0.52 & 81 & -2.5 & $76.4 \pm 2.9$ & $65.1 \pm 3.9$ & 58,000 \\
\hline
\end{tabular}



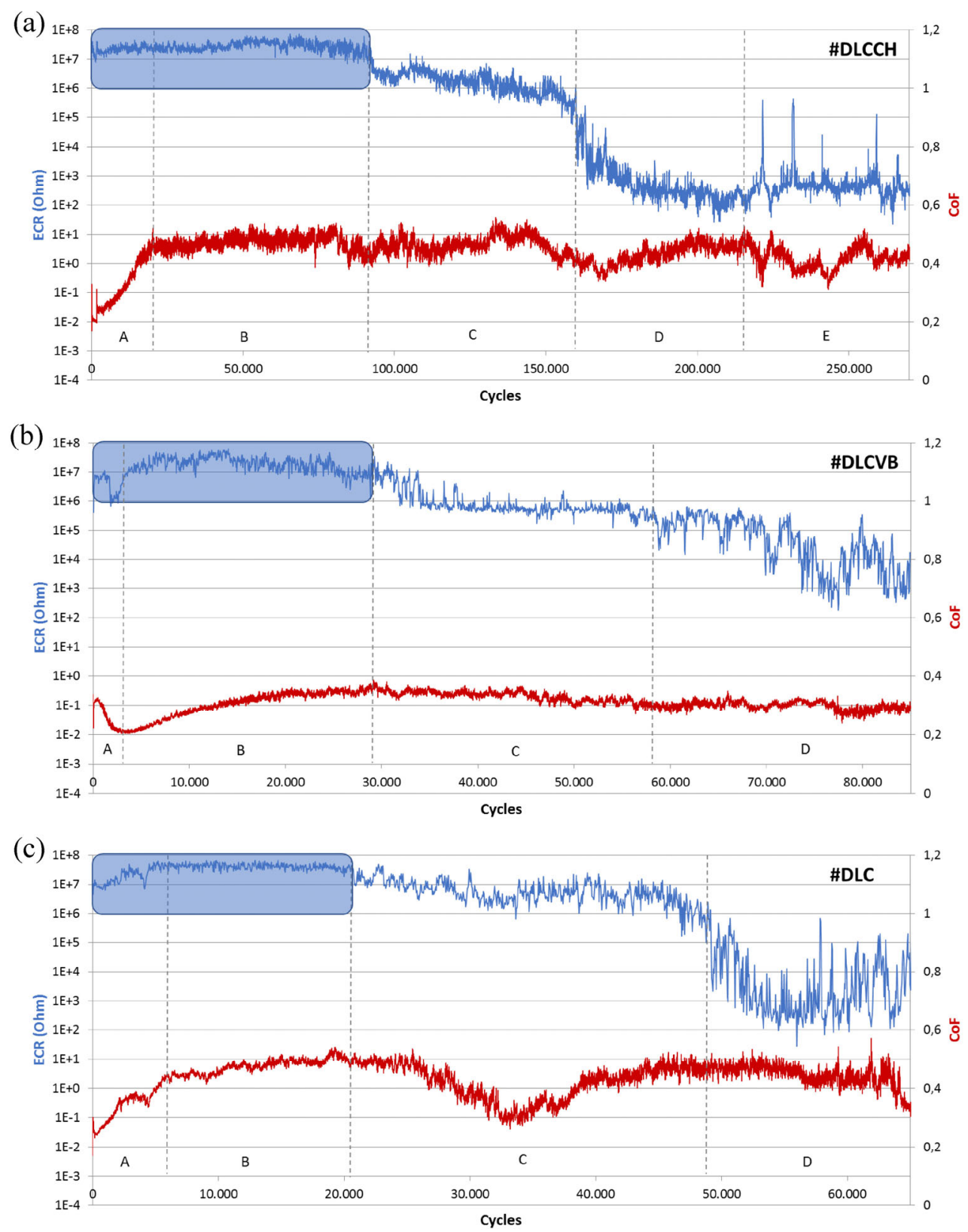

Fig. 1 ECR $(\Omega$; logarithmic scale on the left vertical axis; in blue) and CoF (right vertical axis; in red) evolution of reference\#DLCCH (a), reference\#DLCVB (b), and reference\#DLC (c) coatings against aluminum along the test cycles (horizontal axis) under 50\% RH. Note: shadowed blue area on the left upper side indicates electric resistance values above the upper limit of the ohmmeter.

CoF becoming less steady (Region C in Fig. 1(a)). As the cracks progressed and the adhesion of aluminum increased, facilitated by the openings and increasing roughness in the outer DLC surface, sections of the coating spalled off, and the ECR began to fell remarkably. In this phase, the surface lost its dielectric character, and thus could be considered no longer operational in many applications (Region D in Fig. 1(a)).

In the final stage, significant transfer of material between ball and disk occurred, the interlayer and substrate were reached in certain points, which eventually get oxidized. This was accompanied by fluctuations in both the CoF and ECR. The more intense of these involved a drop in the CoF and a surge in the ECR values, which can be ascribed to the transfer and formation of fully covering DLC layers in the aluminum counterparts. Besides, oxidation of the exposed areas in the copper substrate originated the ECR to increase 


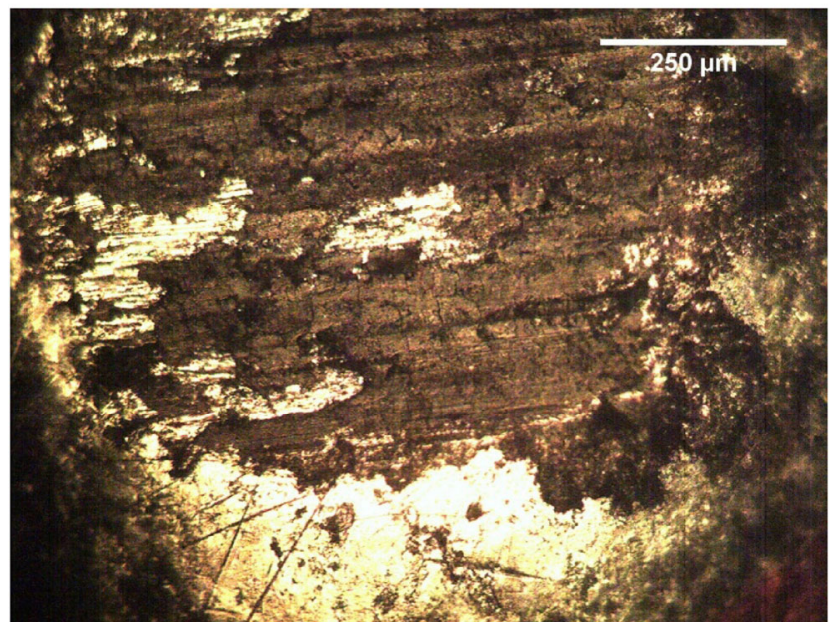

Fig. 2 Micrograph in the OM of the wear track on the Al ball sliding against coating reference\#DLCCH after the electrotribology test.

\section{(Region E in Fig. 1(a)).}

Concerning coating reference\#DLCVB, the run-up performance (Region A in Fig. 1(b)) was different to the other coatings, i.e. the CoF did not rise, but decreased. This reflects rougher character of this coating. In this phase mild wear caused the surface to smoothen, and a graphite rich transfer layer was also formed in the aluminum counterpart (Fig. 3). This was also reflected in a lower overall CoF as compared with the other coatings all along the test.

Coatings reference\#DLCVB and \#DLC being thinner than \#DLCCH, phase $\mathrm{C}$ was reached in fewer test cycles (Region B-C in Fig. 1(b)) in these cases. On the other hand, reference\#DLCVB presenting lower internal stresses caused a lesser occurrence of cracks and spalling off of the coating, which translated in a less abrupt drop in the ECR values (Region D-E in Fig. 1(b)). The fact that reference\#DLCVB and \#DLC were thinner also originated an overlap of phases D and E, as the spall off of sections of the coating did reach the interlayer and the substrate easier and faster.

Finally, reference\#DLC showed a run up and abrupt ECR drop phases similar to that of reference\#DLCCH (Regions A and D in Fig. 1(c)), but shorter coating life and an overlap of phases $\mathrm{D}$ and $\mathrm{E}$ like reference\#DLC (Regions B-C and D-E in Fig. 1(c)).

Overall, operative coating life, i.e. as a dielectric coating in the $A+B+C$ regions, ranged from 48,000 and 58,000 cycles for references \#DLC and \#DLCVB,

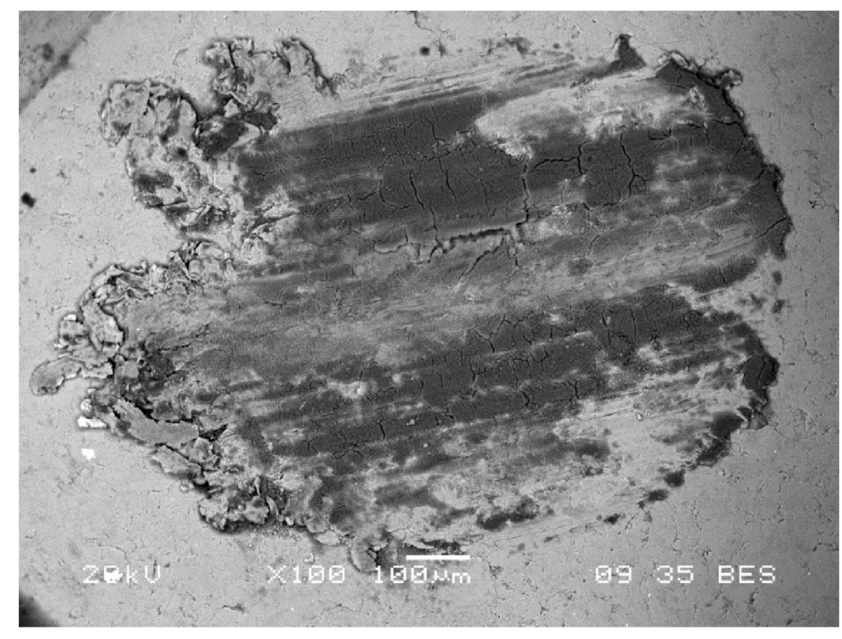

Fig. 3 SEM image (Backscattering spectrometry) of the wear track on the Al ball against coating reference\#DLCVB, $\times 100$.

respectively, to 161,000 cycles for reference \#DLCCH (as listed in Table 2).

Figures 4 and 5 show the wear tracks on the coatings after the wear tests. The backscattered SEM images in Fig. 5 show four distinct tones: black, corresponding to adhered aluminum, dark grey corresponding to the copper substrate, light grey corresponding to the DLC coating, and in white the WC interlayer, as depicted in the EDS spectra shown in Fig. 6. Cracks can be observed (1 in Figs. 4 and 5), especially in reference\#DLCCH and \#DLC, which present the largest residual stresses. Actually, the lower the residual stresses the smaller the cracks in the images. There are also plenty of coating spall offs, that often can be associated with the presence of cracks, which expose either the WC interlayer or the copper substrate ( 2 and 3 respectively in Figs. 4 and 5; and Figs. 6(a) and 6(b)). Finally, lots of adhered aluminum can be observed as well (4 in Figs. 4 and 5; and Fig. 6(c)).

Although unfortunately, the tests in the equipment used could not be stopped for surface analysis and reinitiated, certain correlations between the defects observed in Figs. 4 and 5, and the operation regions in Fig. 1 can be figured. Cracks (1 in Figs. 4 and 5) might have initiated and grow along region $\mathrm{C}$, the coating spall offs (2 and 3 in Figs. 4 and 5) along region D, and the massive aluminum adhesion (4 in Figs. 4 and 5) along regions $\mathrm{D}$ and $\mathrm{E}$.

Therefore, some relations can be stablished between the coating features and their tribological properties 
(a)

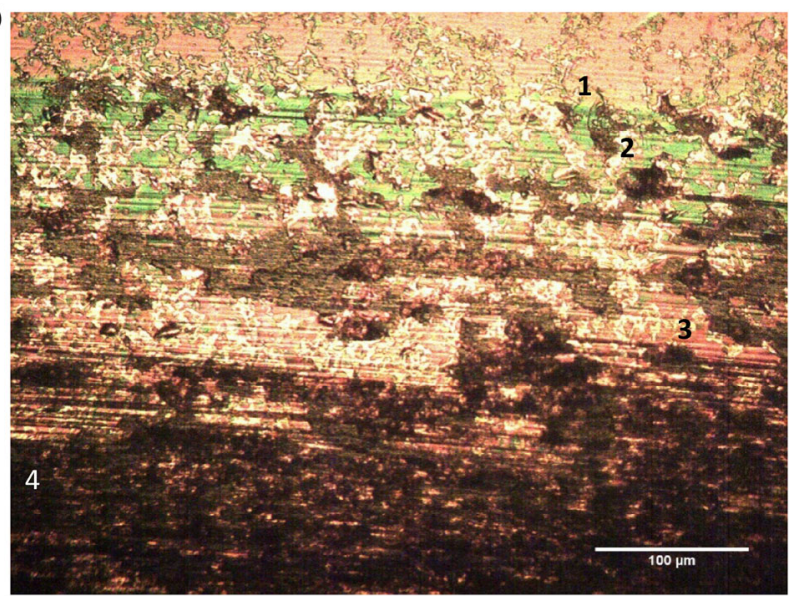

(b)

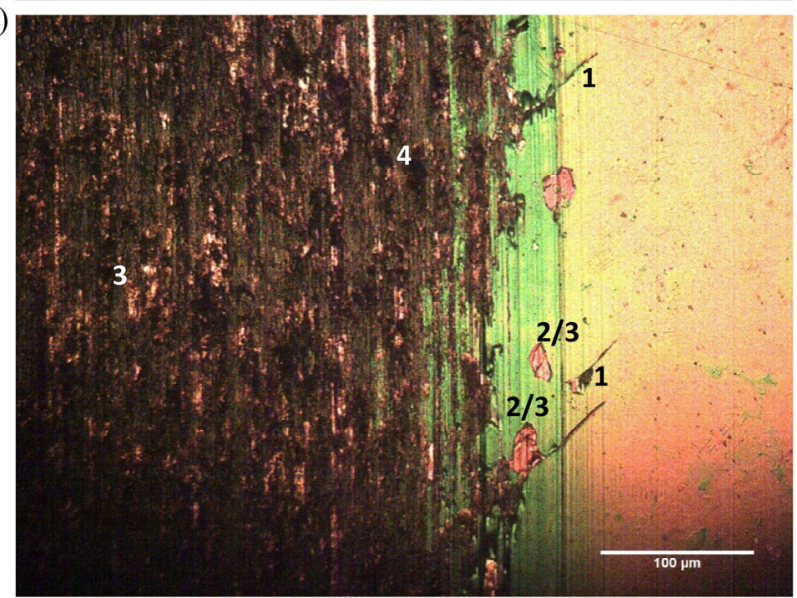

(c)

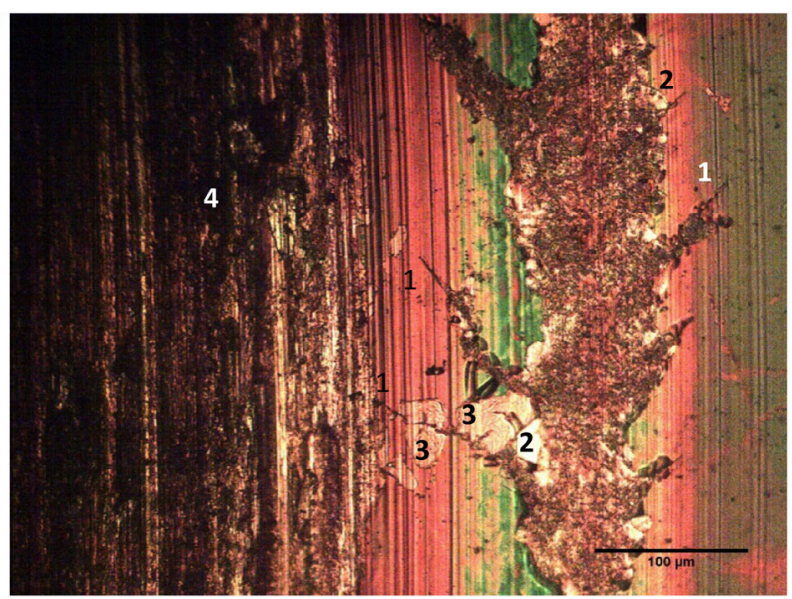

Fig. 4 Micrographs of the wear track of coating reference\#DLCVB (a), \#DLCCH (b), and \#DLC (c) after the electro-tribology test, $\times 200$.

against aluminum. The fact that reference\#DLCCH was thicker than references\#DLC and \#DLCVB contributed to the more prolonged coating life. It did also cause an abrupt drop of the dielectric features (high to low ECR), due to the spall off of the coating. This abrupt fall in ECR was also observed in \#DLCCH (a)

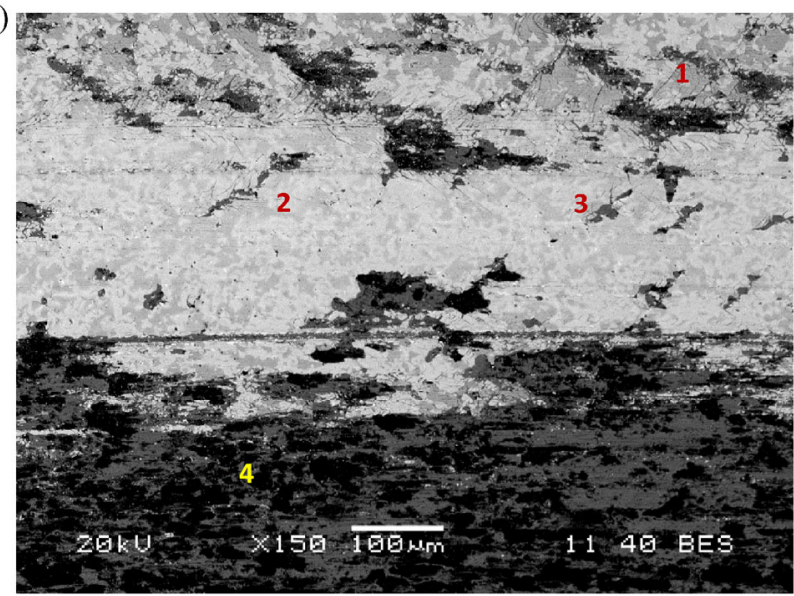

(b)

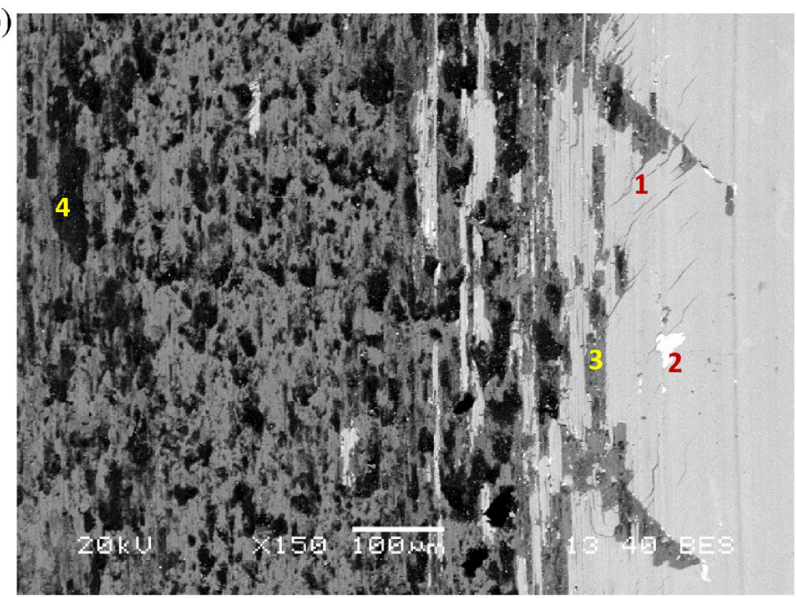

(c)

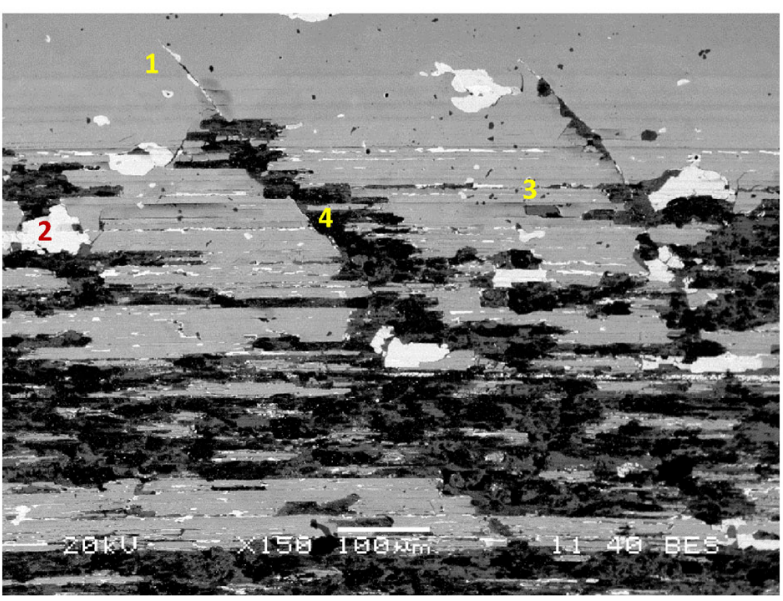

Fig. 5 Scanning electron microscope (backscattering) images of the wear track of coating reference\#DLCVB (a), \#DLCCH (b), and \#DLC (c) after the electro-tribology test, $\times 150$.

as compared with \#DLCVB, with similar coating thicknesses, in this case because of the big difference in their residual stresses. Coating roughness has only affected the initial stages of the electro-tribology tests, as observed in reference\#DLCVB with a rougher surface (Fig. 1), till the surface finishing flattened out. 

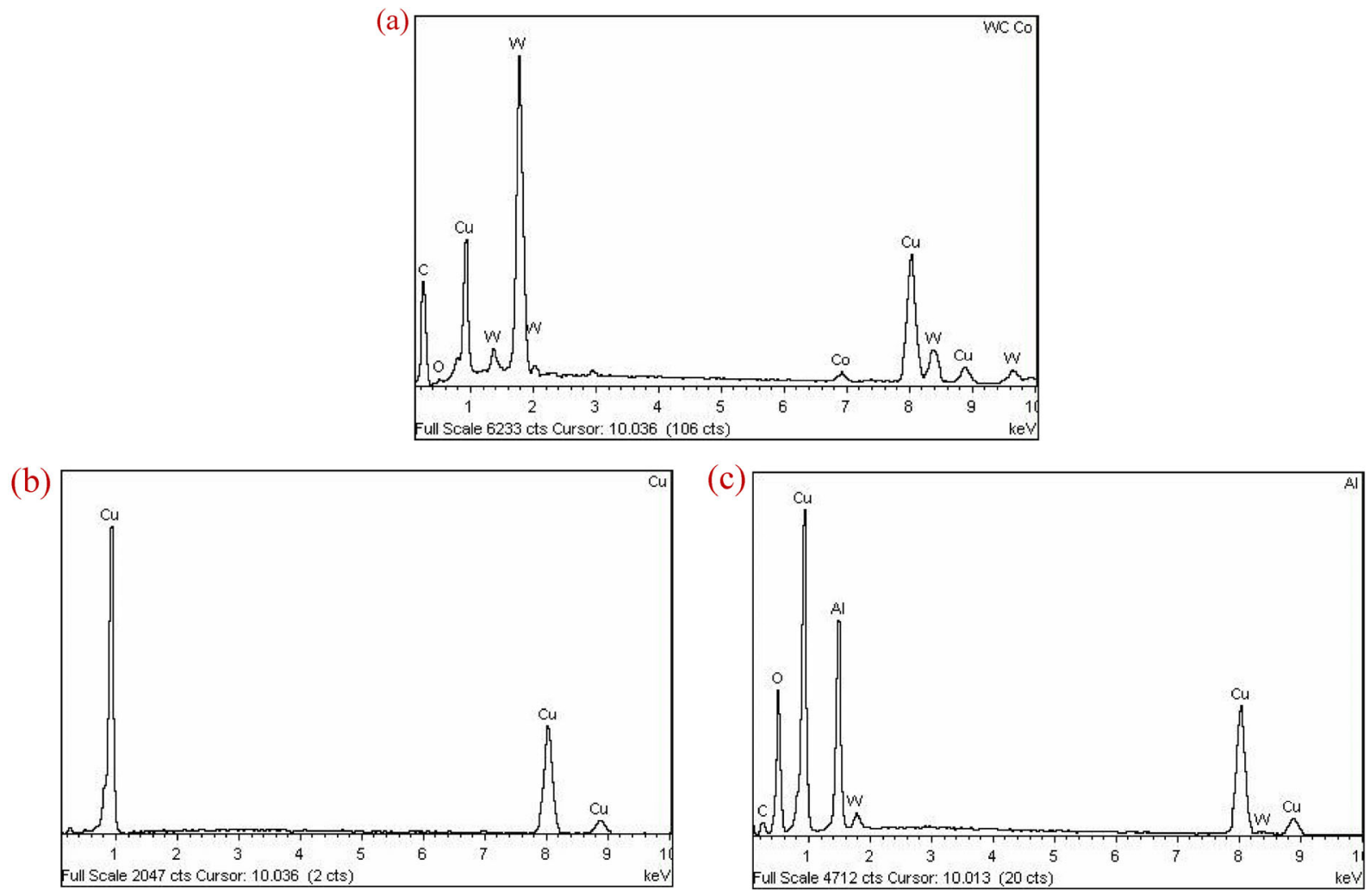

Fig. 6 (a), (b), and (c): EDS on the wear track of coating reference\#DLC on defects type 2, 3, and 4 as shown in Fig. 5(c).

On the other hand, the coating hardness and wettability seems to not have played a relevant role. In the case of the coating hardness, they were quite similar $(I(D) / I(G)$ and harder than the aluminum counterpart. In the case of the wettability, the three surfaces were mildly hydrophilic and also quite similar to make a difference (Table 2): \#DLC $=63.5^{\circ} \pm 2.0 ; \# \mathrm{DLCCH}=$ $70.5^{\circ} \pm 0.5 ; \# \mathrm{DLCVB}=65.1^{\circ} \pm 1.9$. However, the mildly hydrophilic feature of the coatings did make a difference with the relative humidity at which test were performed was changed, as detailed in the next section.

Tribological properties of DLC coatings are known to be highly dependent on the relative percentage of humidity $(\% \mathrm{RH})$ of the surrounding atmosphere [8-10, 15, 44, 45]. Therefore, the electro-tribology properties of coating ref. \#DLC were also studied at different percentages of relative humidity: $10 \%, 50 \%$, and $90 \%$ (Fig. 7).

It was found that increasing values of relative humidity caused an extension of the coating life (as a dielectric coating). It reached 17,000 cycles at $10 \%$ $\mathrm{RH}$, but lengthened to 48,000 cycles at $50 \% \mathrm{RH}$, and to 60,000 cycles at $90 \% \mathrm{RH}$. On the contrary, lower
$\mathrm{RH}$ corresponded with lower CoF. This trend is in accordance with results published elsewhere [9, 10], which have also observed higher CoF values as the relative humidity increased, although the precise characteristics of the DLC coating and tribological tests conditions were not exactly the same, and overall $\mathrm{CoF}$ values were lower [46]. One of the reasons argued consists on the deceleration of the graphitization of the coating due to humidity, which prevents formation of hot spots, and blocks the adsorption and diffusion of hydrogen atoms [24]. The increase of the CoF of hydrogenated DLC coatings in humid air has also been attributed to the increase in the van der Waals bond strength of hydrogen bonding to adsorbed water molecules compared to hydrocarbons [47].

It should also be noted that the CoF values measured in this work are relatively high as compared with values reported elsewhere. One of the reasons might be that the degree of graphitization of the DLC coating has been relatively low, due to the formation of few hot spots because the aluminum counterpart is a good thermal conductor, and the contact load was relatively small [19]. In our case, DLC on copper substrate, the 


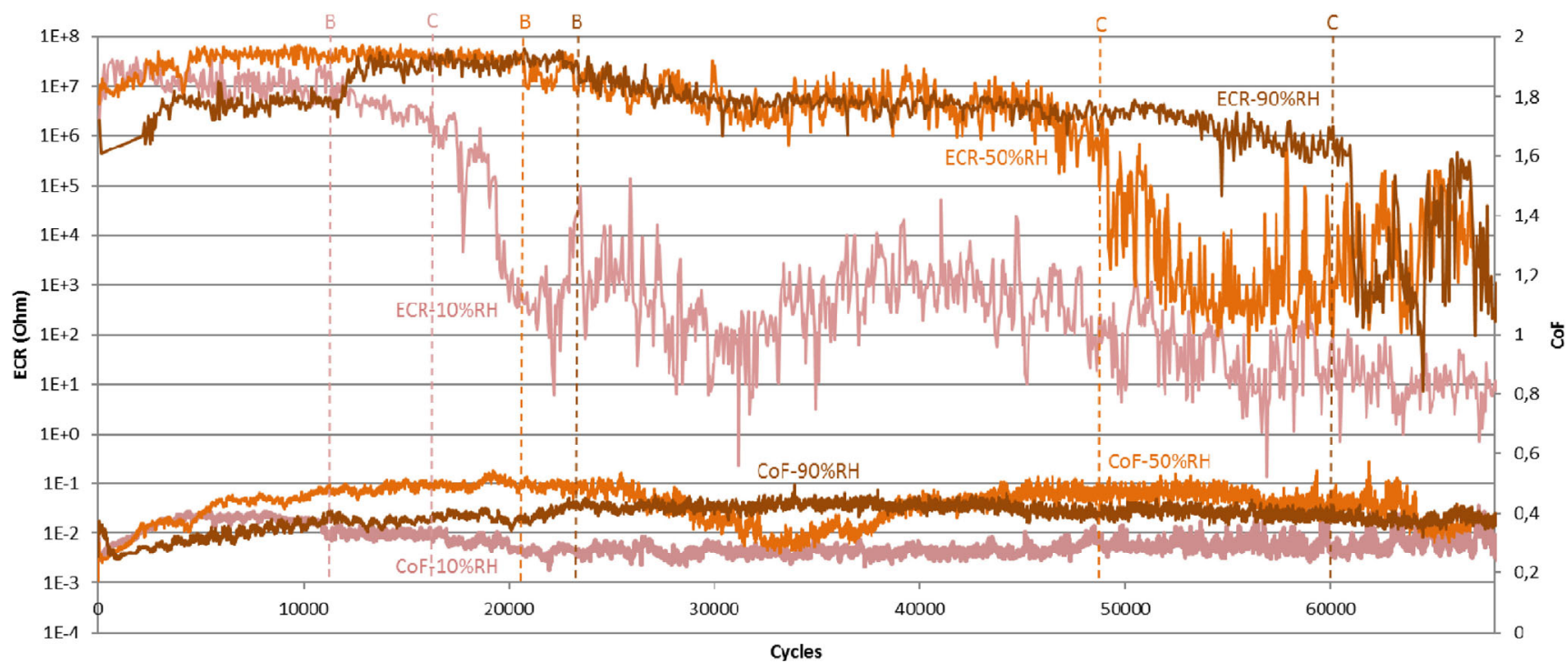

Fig. 7 ECR ( $\Omega$; logarithmic scale on the left vertical axis; above) and CoF (right vertical axis; below) evolution of ref. \#DLC coatings against aluminum along the test cycles (horizontal axis), at different relative percentages of humidity: $10 \%, 50 \%$, and $90 \%$.

level of oxidation of the outer copper surface, exposed by the wear of the coating, could also have played a role, as the low humidity $(10 \% \mathrm{RH})$ test have shown both lower CoF and ECR as compared to higher humidity conditions once the coating worn out. Otherwise, the ECR performance and evolution of the coating was qualitatively similar, independent of the relative humidity.

Finally, it could be expected that in more hydrophobic DLCs, such as those of ref. \#DLCCH and \#DLCVB, the drop in operative life of the coating to occur at higher levels of relative humidity as compared to those of coating \#DLC.

\section{Conclusions}

The DLC coatings studied in this work have shown varying dielectric and tribological features, that are affected by the surrounding humidity.

Additionally, ECR have proved to be a good monitoring tool for the status of the DLC coatings studied, independently of the working media, i.e. relative humidity. Formation of cracks, spalling off of the coating, adhesive wear, and surface oxidation are behind the coating degradation when tested against aluminum. This degradation can be tracked by the evolution of the ECR, in such a way that the coating operational life could be defined predictively. None- theless, future investigations should cover a broader range of DLC coatings, to deepen the understanding of the correlations between tribological performance and ECR.

Therefore, electro-tribological data has demonstrated to be potentially useful in the framework of coating development and optimization, as it provides key information about the failure modes. Additionally, it could prove useful in on-line monitoring systems of the degradation of coated parts in operation.

\section{Acknowledgements}

This work was financially supported by FUTURE GRIDS-2020, Frontiers, and nG-17 projects (Elkartek, Economic Development Department at the Basque Government).

Open Access: This article is licensed under a Creative Commons Attribution 4.0 International License, which permits use, sharing, adaptation, distribution and reproduction in any medium or format, as long as you give appropriate credit to the original author(s) and the source, provide a link to the Creative Commons licence, and indicate if changes were made.

The images or other third party material in this article are included in the article's Creative Commons licence, unless indicated otherwise in a credit line to 
the material. If material is not included in the article's Creative Commons licence and your intended use is not permitted by statutory regulation or exceeds the permitted use, you will need to obtain permission directly from the copyright holder.

To view a copy of this licence, visit http://creativecommons.org/licenses/by/4.0/.

\section{References}

[1] Grill A. Diamond-like carbon: State of the art. Diam Relat Mater 8(2-5): 428-434 (1999)

[2] Grill A. Electrical and optical properties of diamond-like carbon. Thin Solid Films 355-356: 189-193 (1999)

[3] Bansal D G, Streator J L. Effect of operating conditions on tribological response of Al-Al sliding electrical interface. Tribol Lett 43(1): 43-54 (2011)

[4] Zhang Y Z, Yang Z H, Song K X, Pang X J, Shangguan B. Triboelectric behaviors of materials under high speeds and large currents. Friction 1(3): 259-270 (2013)

[5] Hombo R, Takeno T, Fontaine J, Miki H, Kato N, Nozu T, Inayoshi N, Belin N, Tagaki $\mathrm{T}$. Tribological and electric contact behaviour of metal/DLC nanocomposite coating on brass substrate. In 40th Leeds-Lyon Symposium on Tribology \& Tribochemistry Forum 2013, Lyon, France, 2013.

[6] He M Y, Lee S, Yeo C D. Investigating atomic structure of thin carbon film under mechanical stress and frictional heat generation. Surf Coat Technol 261: 79-85 (2015)

[7] Jiang X J, Pan F Q, Shao G Q, Huang J, Hong J, Zhou A C. Prediction of electrical contact endurance subject to micro-slip wear using friction energy dissipation approach. Friction 1-14 (2018) doi: 10.1007/s40544-018-0230-x

[8] Fan X Q, Xue Q J, Wang L P. Carbon-based solid-liquid lubricating coatings for space applications-A review. Friction 3(3): 191-207 (2015)

[9] Erdemir A, Eryilmaz O. Achieving superlubricity in DLC films by controlling bulk, surface, and tribochemistry. Friction 2(2): 140-155 (2014)

[10] Sutton D C, Limbert G, Stewart D, Wood R J K. The friction of diamond-like carbon coatings in a water environment. Friction 1(3): 210-221 (2013)

[11] Vetter J. 60 years of DLC coatings: Historical highlights and technical review of cathodic arc processes to synthesize various DLC types, and their evolution for industrial applications. Surf Coat Technol 257: 213-240 (2014)

[12] Donnet C, Erdemir A. Tribology of Diamond-like Carbon Films Fundamentals and Applications. New York (USA): Springer, 2008.
[13] Miyake S, Shindo T, Miyake M. Deposition and tribology of electroconductive and wear-resistant nanocomposite solid lubricant films composed of carbon and silver or gold. Tribol let 61(1): 6 (2016)

[14] Grandin M, Wiklund U. Influence of mechanical and electrical load on a copper/copper-graphite sliding electrical contact. Tribol Int 121: 1-9 (2018)

[15] Bewilogua K, Braüer G, Dietz A, Gäbler J, Goch G, Karpuschewski B, Szyszka B. Surface technology for automotive engineering. CIRP Ann 58(2): 608-627 (2009)

[16] Field S K, Jarratt M, Teer D G. Tribological properties of graphite-like and diamond-like carbon coatings. Tribol Int 37(11-12): 949-956 (2004)

[17] Oñate J I, Comin M, Braceras I, Garcia A, Viviente J L, Brizuela M, Garagorri N, Peris J L, Alava J I. Wear reduction effect on ultra-high-molecular-weight polyethylene by application of hard coatings and ion implantation on cobalt chromium alloy, as measured in a knee wear simulation machine. Surf Coat Technol 142-144: 1056-1062 (2001)

[18] Brizuela M, Garcia-Luis A, Viviente J L, Braceras I, Oñate J I. Tribological study of lubricious DLC biocompatible coatings. J Mater Sci Mater Med 13(12): 1129-1133 (2002)

[19] Grill A. Tribology of diamondlike carbon and related materials: An updated review. Surf Coat Technol 94-95: 507-513 (1997)

[20] Liu Y, Erdemir A, Meletis E I. A study of the wear mechanism of diamond-like carbon films. Surf Coat Technol 82(1-2): 48-56 (1996)

[21] Liu Y, Erdemir A, Meletis E I. An investigation of the relationship between graphitization and frictional behavior of DLC coatings. Surf Coat Technol 86-87: 564-568 (1996)

[22] Erdemir A. Genesis of super-low friction and wear in diamondlike carbon films. Tribol Int 37(11-12): 1005-1012 (2004)

[23] Luo D B, Fridrici V, Kapsa P. A systematic approach for the selection of tribological coatings. Wear 271(9-10): 2132-2143 (2011)

[24] Liu Y, Erdemir A, Meletis E I. Influence of environmental parameters on the frictional behavior of DLC coatings. Surf Coat Technol 94-95: 463-468 (1997)

[25] Tian P Y, Tian Y, Shan L, Meng Y G, Zhang X J. A correlation analysis method for analyzing tribological states using acoustic emission, frictional coefficient, and contact resistance signals. Friction 3(1): 36-46 (2015)

[26] Vakis A I, Yastrebov V A, Scheibert J, Nicola L, Dini D, Minfray C, Almqvist A, Paggi M, Lee S, Limbert G, et al. Modeling and simulation in tribology across scales: An overview. Tribol Int 125: 169-199 (2018) 
[27] Clarke A, Weeks I J J, Evans H P, Snidle R W. An investigation into mixed lubrication conditions using electrical contact resistance techniques. Tribol Int 93: 709-716 (2016)

[28] Bucca G, Collina A. Electromechanical interaction between carbon-based pantograph strip and copper contact wire: A heuristic wear model. Tribol Int 92: 47-56 (2015)

[29] Braceras I, Ibáñez I, Taher M, Mao F, Del Barrio A, de Urturi S S, Berastegui P, Andersson A M, Jansson U. On the electro-tribological properties and degradation resistance of silver-aluminum coatings. Wear 414-415: 202-211 (2018)

[30] Patton S T, Zabinski J S. Advanced tribometer for in situ studies of friction, wear, and contactcondition-Advanced tribometer for friction and wear studies. Tribol Lett 13(4): 263-273 (2002)

[31] Simonovic K, Kalin M. Experimentally derived friction model to evaluate the anti-wear and friction-modifier additives in steel and DLC contacts. Tribol Int 111: 116-137 (2017)

[32] Wang P F, Takagi T, Takeno T, Miki H. Early fatigue damage detecting sensors-A review and prospects. Sens Actuators A Phys 198: 46-60 (2013)

[33] Majdoub F, Belin M, Martin J M, Perret-Liaudet J, Kano M, Yoshida K. Exploring low friction of lubricated DLC coatings in no-wear conditions with a new relaxation tribometer. Tribol Int 65: 278-285 (2013)

[34] Ferrari A C. Determination of bonding in diamond-like carbon by Raman spectroscopy. Diam Relat Mater. 11(3-6): 1053-1061 (2002)

[35] Ferrari A C, Robertson J. Interpretation of Raman spectra of disordered and amorphous carbon. Phys Rev B 61(20): 14095-14107 (2000)

[36] Robertson J. Diamond-like amorphous carbon. Mat Sci and Eng R Rep 37(4-6): 129-281 (2002)

[37] Cui W G, Lai Q B, Zhang L, Wang F M. Quantitative measurements of $\mathrm{sp}^{3}$ content in DLC films with Raman spectroscopy. Surf Coat Technol 205(7): 1995-1999 (2010)

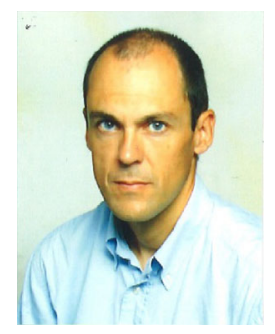

Iñigo BRACERAS. He received his M.S. in industrial (electrical) engineering from University of Navarra (Spain) in 1994, and his Ph.D. degree in mechanical engineering from University of the Basque Country (Spain) in 2019. He
[38] IEC/TS 62073 Guidance on the measurement of wettability of insulator surfaces. Geneva: IEC International Electrotechnical Commission, 2003.

[39] Braceras I, Ibáñez I, Domínguez-Meister S, Urgebain A, Sánchez-García JA, Larrañaga A, Garmendia I. Corrosion preserving high density plasma treatment of precipitation hardening stainless steel. Surf Coat Technol 355: 174-180 (2018)

[40] Deng J G, Braun M. Residual stress and microhardness of DLC multilayer coatings. Diam Relat Mater 5(3-5): 478-482 (1996)

[41] Wang J, Liu G C, Wang L D, Deng X L, Xu J. Studies of diamond-like carbon (DLC) films deposited on stainless steel substrate with $\mathrm{Si} / \mathrm{SiC}$ intermediate layers. Chin Phys B 17(8): 3108-3114 (2008)

[42] Nakamura M, Takagawa Y, Miura K I, Kobata J, Zhu W L, Nishiike N, Arao K, Marin E, Pezzotti G. Structural alteration induced by substrate bias voltage variation in diamond-like carbon films fabricated by unbalanced magnetron sputtering. Diam Relat Mater 90: 214-220 (2018)

[43] Chen Z, Liu P, Verhoeven J D, Gibson E D. Electrotribological behavior of $\mathrm{Cu}-15$ vol.\% $\mathrm{Cr}$ in situ composites under dry sliding. Wear 203-204: 28-35 (1997)

[44] Savage R H. Graphite lubrication. J Appl Phys 19(1): 1-10 (1948)

[45] Deacon R F, Goodman J F. Lubrication by lamellar solids. Proc Royal Soc London. Ser A, Math Phys Sci 243(1235): 464-482 (1958)

[46] Wang F, Lu Z B, Wang L P, Zhang G G, Xu Q J. Effect of tribochemistry on friction behavior of fluorinated amorphous carbon films against aluminum. Surf Coat Technol 304: 150-159 (2016)

[47] Gardos M N. Tribology and wear behavior of diamond. In Synthetic Diamond: Emerging CVD Science and Technology. Spear K E, Dismukes J E, Eds. New York: John Wiley \& Sons, Inc, 1994: 419.

joined the surface engineering group at Tecnalia in 1997, where his current position in senior researcher and project manager. His research areas cover the development, analyses and monitoring of surface treatments and coatings with tribological, protective and functional properties for industrial, transport, energy, and biomedical applications. 


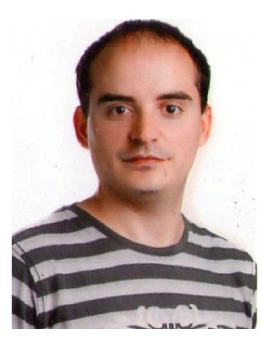

Iñigo IBÁÑEZ. He received his technician at chemical industry processes and laboratory technician degrees from the Paper Technical Engineering School, Tolosa (Spain) in 2001 and 2008, respectively. His

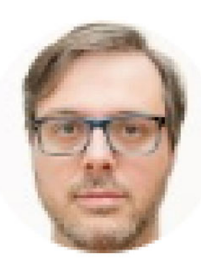

Santiago DOMINGUEZ-MEISTER. He received his M.S. in physics degree from the University of Zaragoza (Spain) in 2008, and his Ph.D. degree on materials sciences from the University of Sevilla (Spain) in 2013.

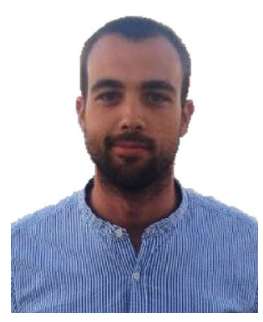

Xabier VELASCO. He received his bachelor degree in electrical engineering in 2015 from University of the Basque Country, DonostiaSan Sebastian (Spain). Likewise, he

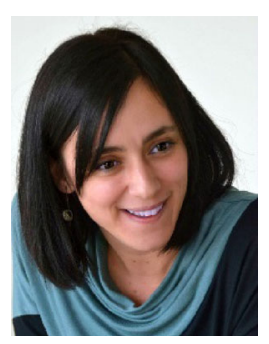

Marta BRIZUELA. She received her M.S. degree in physics from the University of Valladolid (Spain) in 1997, and her Ph.D. degree in physics science from the University of the Basque Country (Spain) in 2009. Her current position is head

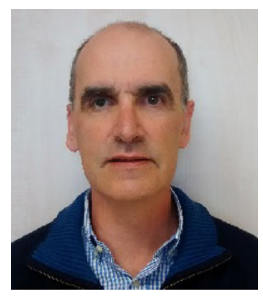

Iñaki GARMENDIA. He received his M.S. and Ph.D. degrees in mechanical engineering from University of Navarra (Spain) in 1987 and 1994, respectively. He worked for Inasmet-Tecnalia, a materials research center, from 1998 to 2010 mainly in the field current position is head of the Surface Engineering Laboratory at Tecnalia. His research interests are plasma-based surface treatments, thin film deposition, surface characterization and analyses, and tribological studies.

His current position is researcher in the surface engineering group at Tecnalia. His research areas cover the development of surface treatments and thin films, as well as the study of their tribological properties.

received his M.S. in renewable materials engineering in 2016 in the same University. His research interests are electro-tribological studies and dielectric spectroscopy of thin films made of nanocomposites of polymeric and metallic nanoparticles.

of surface engineering group within the materials group for Energy and Environment department at Tecnalia. Her research areas cover thin films development (plasma assisted technologies) for different applications (wear, corrosion protection, and functional properties).

of computational modeling and materials. In 2010 he joined the Mechanical Engineering Department of the University of the Basque Country as a full-time lecturer. His research interests are numerical simulation of materials processes, electro-tribological modeling, and space thermal control. 